\title{
Salgın Dönemi Kulüp Hisse Değerlerinde Ekonomik Kayıplar (Trend Analizi)*
}

\author{
Zühal YURTSIZOĞLU ${ }^{1 \dagger}$ \\ ${ }^{1}$ Sivas Cumhuriyet Üniversitesi, Spor Bilimleri Fakültesi, Sivas, Türkiye
}

Orijinal Makale

Gönderi Tarihi: 10.09.2021
Kabul Tarihi: 25.12.2021
DOI:10.47778/ejsse.993657

Online Yayın: 31.12. 2021

\section{$\ddot{O} \mathbf{z}$}

Covid-19 küresel salgını, milyarlarca insanın taraftar ve tüketici olarak yer aldığı futbol ekonomisinde, büyük gelir kayıplarına neden olmuştur. Salgın döneminde sponsorluk gelirleri, yayın gelirleri, maç hasılatı ve reklam gelirlerinde düşüş yaşayan kulüplerin, BİST (Borsa İstanbul) hisselerinde dalgalanmalar ve ekonomik kayıplar yaşanmıştır. Bu çalışma, Türkiye Süper Lig'de bulunan ve hisselerini borsaya açmış olan 4 büyük spor kulübünün (Fenerbahçe, Galatasaray, Beşiktaş, Trabzonspor) yaşadığı, ekonomik kayıpları ortaya koymak için yapılmıştır. Bu amaçla BİST'e kayıtlı kulüplere ilişkin hisse değerleri, enflasyondan arındırılıp, ortalamaları alındıktan sonra, trend analizi yapılmıştır. Trend analizi ile kulüp hisselerinde ortaya çıkan değer kayıpları ve eğilimler ortaya konulmaya çalışılmıştır. Çalışmanın sonucunda, salgın döneminde, sektörde alınan kararların hisse senetlerine tarihler itibari ile yansıdığı gözlemlenmiştir. Kulüplerin hisse senedi ortalamalarında, baz yıl ve bir önceki aya göre yaklaşık \%50'lere varan değer kayıpları hesaplanmıştır. Çalışmanın, Covid-19 salgını ile mücadele eden futbol ekonomisine 1 şık tutacağı düşünülmektedir.

Anahtar Kelimeler: Kulüp, Salgın, Futbol, Trend analizi

\section{Economic Losses in Club Values in The Pandemic Period (Trend Analysis)}

\begin{abstract}
The Covid-19 global pandemic has caused huge income losses in the football economy, where billions of people are involved as fans and consumers. During the pandemic period, the sports clubs that experienced a decrease in sponsorship revenues, broadcasting revenues, match revenues and advertising revenues experienced fluctuations and economic losses in BIST (Borsa Istanbul) shares. This study was carried out to reveal the economic losses experienced by the 4 big clubs in the Turkish Premier League, which opened their shares to the stock market. For this purpose, after the stock values of the clubs registered in the BIST were adjusted for inflation and their averages were taken, trend analysis was performed. With the trend analysis, the depreciation and trends in club stocks were tried to be revealed. As a result of the study, it was observed that the decisions taken in the sector during the pandemic period were reflected in the stocks as of dates. In the average of the stocks of the clubs, depreciation of up to $50 \%$ was calculated compared to the base year and the previous month. It is thought that the study will shed light on the football economy struggling with the pandemic.
\end{abstract}

Keywords: Club, Pandemic, football, Trend analysis

\footnotetext{
* Bu çalışma "Balkan Summit 4. Internatıonal Socıal Scıences Congress" sözlü (özet) bildiri olarak sunulan çalışmanın genişletilmiş halidir.

† Sorumlu Yazar: Zühal YURTSIZOĞLU, E-posta: yurtsiz@gmail.com
} 


\section{GíRiş}

Ekonomide liberalleşmenin yoğun olarak yaşandığı 1980'li yıllar ve sonrasında futbol ekonomisi; maç günü bilet satışları, sponsorluk gelirleri, yayın gelirleri, reklam gelirleri, bonservis ve transfer gelirleri, lisanslı ürün satışları ile spor endüstrisinin içinde büyük bir ekonomik güce dönüşmüştür (Akşar, 2005). Spor endüstrisi; profesyonel ve amatör takımların, liglerin, organizasyonların ve spor aktivitelerinin yer aldığı, spor organizasyonlarının yönetildiği, şirketleşmiş spor takımlarının bulunduğu büyük bir endüstridir (Taşkın ve Eren, 2016). 2019 yılı verilerine göre bu dev endüstrinin toplam değerinin 614 milyar dolara ulaştığı düşünülmektedir (Business Wire, 2020). $\mathrm{Bu}$ büyük parasal değerin içinde futbol ekonomisinin oranı oldukça büyüktür. 2020 yılında spor endüstrisinin değerinin 1 trilyon dolar olacağı tahmin ediliyordu. Fakat küresel salgın, tüm sektörlerde olduğu gibi spor endüstrisini de derinden etkilemiş, kulüplerin gelirlerini baltalamıştır. Hatta bilet satışları gibi, bazı gelir kaynakları bir dönem sıfırlanmıştır. Gelir akışındaki bu azalışlar karşısında, giderleri artan kulüpler, derin ekonomik krizlerle karşı karşıya kalmıştır (Yurtsızoğlu, 2021).

Küreselleşme ekonomik anlamda, tüm endüstrilerde olduğu gibi spor endüstrisine de farklı bakış açıları getirmiştir. Dünyada önemli etkilere ve büyüklüklere sahip olan çok uluslu işletmeler, spor organizasyonları ile spor endüstrisinin içine dahil olmaya başlamış ve spor, ticari bir sektör haline dönüşmüştür. Spor organizasyonları ve etkinlikler, eğlence sektörüne dahil edilmeye başlayınca, spor, tüketim kalıbına bürünerek pazarlanmaya başlamıştır (Authier, 2002). Spor kulüplerinin şirketleşme ve ekonomik gelişim süreçleri, sporun ticari bir ürün gibi pazarlanması düşüncesiyle, kulüplerin anonim şirket şeklinde yapılanarak, hisselerini borsada halka sunmasına kadar gitmiş̧ir. $\mathrm{Bu}$ anlamda kulüpler için, borsa önemli bir gelir kaynăg 1 haline dönüşmüştür. Fenerbahçe, Galatasaray, Beşiktaş, Trabzonspor, daha düşük maliyette fon temin elde edebilmek için ve şirketleşen kulüplerine gelir yaratmak için, hisselerini halka arz etmiş, daha kurumsal hale dönüşerek sermaye piyasalarından gelir elde etmeye başlamışlardır (Karadeniz ve Kahiloğullari, 2014).

Şirketlerin, finansman kaynağı sağlamak için hisselerini halka arz ederek fon sağlamaları, diğer fon sağlama yöntemlerine göre daha caziptir. Çünkü bu yöntemde, fonların geri ödenmesi durumunda, her hangi bir vade yoktur. Şirket, borç finansmanında olduğu gibi, bir vade sonunda sabit bir ödeme yapmak zorunda değildir. Aynı zamanda Şirketler bu yöntemle, uzun vadeli bir gelir kaynağına ulaşmış olur. Dahası şirketler borsada işlem gören hisse senetlerini teminat olarak gösterip, kredi kullanabilmekte ve hisse fiyatlarına olumlu bir güven yaratarak, gelecekte daha fazla hisse satabilmektedir. Bu hisse satışları ile işletmeler gelirlerini düzenli bir şekilde arttırabilmektedirler (Güngör, 2020).

Borsa, işletme gelirlerinin düzenli artışını sağlaması, işletme için uzun vadeli gelir kaynağı olması ve risksiz bir borçlanma aracı olduğundan, Spor kulüpleri için de önemli ve cazip bir gelir kaynağı haline dönüşmüştür. Bu yolla kulüpler hisselerini halka arz ederek uzun vadede daha düşük 
maliyette fon temin etmiş ve sermaye piyasasından gelir elde etmeye başlamışlardır. Halka açık tüm şirketlerde olduğu gibi, 4 büyük futbol kulübünde (Fenerbahçe, Galatasaray, Beşiktaş, Trabzonspor) de borsa, önemli bir gelir kaynağı olmasının yanı sıra, kurumsallaşmanın ve prestij kazanmanın bir simgesi haline dönüşmüştür.

Şirketleşen profesyonel futbol faaliyeti gösteren spor kulüplerinin en önemli gelir kaynaklarından biri, maç hasılatı da denilen bilet satışlarından elde edilen gelirlerdir. Kulüpler genel olarak bir sezon boyunca satılan kombine biletlerden gelir elde ederler. Bu önemli gelir, ancak stadyumda maç varsa ortaya çıar. Pandemi ile beraber, ertelenen ya da sonradan seyircisiz oynanan tüm maçlar nedeniyle, futbol ekonomisi ve kulüpler, maç hasılatı gelirinden büyük oranda yoksun kalmıştır. 19 Mart 2020 tarihinde Süper Lig süresiz olarak iptal edilince kulüplerin maç hasılatı gelirleri kesintiye uğramış, süreçle ilgili belirsizlik ekonomik olarak hisse değerlerine de yansımıştır. Haziran 2020'de, Süper ligde ertelenen maçların seyircisiz de olsa oynanması kararı, sektörü yeniden hareketlendirmiştir. Yeni sezon başlangıcı olan, 11 Eylül tarihinde, maçların \%30 seyirci kapasitesi ile oynanmaya başlamasıyla, sektörün bilet satış gelirleri az da olsa yeniden canlanmış ve ekonomik belirsizliklerle ilgili kaygılar azalmaya başlamıştır.

Futbol ekonomisinde parasal anlamda ortaya çıkan büyüklüğün temelinde, diğer bir gelir kaynağı, TV ve yayın gelirleridir. Naklen yayın gelirleri, lig ve kulüpler için önemli bir gelir kaynağıdır. TV ve yayın kuruluşları; liglerin, müsabakaların ve kulüplerin yayın haklarını, ihalelere girerek satın alırlar. Bu satışlar karşılığında kulüplerin ve liglerin elde ettiği bu yayın gelirlerinde, Covid19 küresel salgın döneminde, iptal edilen ve ertelenen maçlar nedeniyle büyük kayıplar yaşanmıştır.

Kulüpler ve ligler için önemli bir diğer gelir kaynağı, reklam ve sponsorluk gelirleridir. İşletmeler için ürettikleri mal ve hizmeti görünür kılmanın ve geniş tüketici kitlelerine ulaşmanın önemli bir yolu, reklam ve sponsorluk anlaşmalarıdır. Futbol, taraftarı ve izleyici kitlesi ile işletmeler için oldukça büyük bir pazardır. İşletmeler ve kurumlar, kulüplere ve liglere sponsor olup, reklam vererek bu büyük pazara ulaşmaya çalışırlar (Bebek, 2017). Bazen de yapılan sponsorluk anlaşmaları ile işletme ve şirketler vergi muafiyetleri elde edebilirler (Kurumlar Vergisi Kanunu, 2016). Bu avantajları nedeniyle işletmeler; kulüpler ve liglere reklam vererek ya da sponsor olarak yüksek bedeller ödeyebilmektedir. Salgın döneminde, maç ve liglerin ertelenmesiyle bu gelirlerde de doğal olarak azalmalar meydana gelmiştir.

Tüm işletmelerde olduğu gibi, şirketleşen spor kulüplerinin temel amacı, elbette hizmet sunarken kar elde etmektir. Çok basit bir yaklaşımla muhasebe ve finansal anlamda, gelirlerin giderlerden fazla olan bölümü kar olarak telaffuz edilir. Fakat pandemi, kulüplerin tüm gelirlerinde olduğu gibi, borsa gelirlerini de etkilemiştir. Çalışma, Covid-19 Küresel salgını döneminde süper ligde yer alan ve hisseleri BİST’te (Borsa İstanbul) işlem gören, 4 büyük kulübün hisse senetlerinde meydana gelen ekonomik değer kayıplarını incelemek amacıyla yapılmışır. BİST’ten alınan veriler bir dizi işlemden geçirilerek, trend analizine tabi tutulmuştur. Çalışmada trend analizi 
yöntemi kullanılarak, salgında ortaya çıkan değer kayıpları analiz edilmiş, bu kayıpların telafileriyle ilgili çözüm önerileri oluşturulmaya çalışılmıştır. Çalışma, hala devam eden salgında futbol ekonomisinin bir bölümüne dahi olsa ışı tutması ve potansiyel çözüm önerileri sunması açısından önemlidir.

\section{YÖNTEM}

\section{Çalışma Grubu}

Türkiye'de, en üst profesyonel lig olan Süper Lig'de, hisselerini halka arz etmiş olan ve BİST'te işlem gören, Fenerbahçe Spor Kulübü, Beşiktaş Jimnastik Kulübü, Galatasaray Spor Kulübü, Trabzonspor Kulübü, çalışmaya dahil edilmiştir. Analiz, Aralık 2019-Mayıs 2021 tarihleri arasında, 18 aylık dönemi kapsamaktadır. Araştırma, çalışmanın dahil edildiği aylarda ortaya çıkan durumu yansıtan, kesitsel bir çalı̧̧madır. Çalışmada, hisse değerlerindeki değiş̧iklikler, maç tarihleri de dikkate alınarak, pandemi koşullarında değerlendirilmiştir.

\section{Verilerin Analizi}

Çalışma verileri, Borsa İstanbul (BİST), Kamu Aydınlatma Platformu (KAP) ve İş Yatırım'ın resmi sitelerinden alınmıştır. Öncelikle, kulüplerin belirlenen aylara ilişkin günlük hisse fiyatlarına ulaşılmıştır. Bu günlük hisse fiyatlarının günlük ağırlıklı ortalamaları hesaplanmışsır. Günlük ağırlıklı ortalamalar, enflasyondan arındırılmıştır. Bu günlük değerlerden tek bir ortalama değere ulaşılmış ve ilgili aya ait, tek bir ortalama hisse fiyatına ulaşılmıştır. Çalışmaya dahil edilen 18 ay için hesaplanan bu hisse fiyatları, trend analizine tabi tutulmuştur. Trend analizinde bir baz döneme ihtiyaç vardır. Çalışmada, yukardaki işlemlerin tümü, 2019 yılına uygulanarak 2019 yılı için bir ortalama fiyata ulaşılmıştır. Bu ortalama değer, baz yıl değeri olarak alınmıştır. Baz yıldan hareketle, pandemi süresince borsadaki hisselerin değer değişiklikleri analize tabi tutulmuştur. Bu işlemlerin tümü, yazar tarafından 4 büyük kulüp için ayrı ayrı hesaplanmış ve grafiklere aktarılmıştır.

Çalışmada, aritmetik ortalama, ağırlıklı ortalamalar, düzeltme işlemleri, enflasyondan arındırma, aylık \% değişimler ve trend analizi yapılmıştır. Trend analizi (eğilim yüzdeleri) tekniğinde, işletmelerin geçmiş dönemdeki finansal hareketleri, yıllar veya dönemler itibari ile analiz edilir. Geçmiş dönemlerde saptanan eğilimlerin yönü, yani artış veya azalışlar incelenen dönemlere 1şık tutar. Trend analizi yönteminde, bir baz dönem vardır. Bu baz döneme ait tutarlar 100 kabul edilir. Diğer verilerin baz yıla göre \% değişimi hesaplanır. Böylece, finansal kalemlerin artış ve azalışları belirlenerek şirketin gelişim ve gerileme gösterdiği dönemler analiz edilir (Dalifinans, 2021). 


\section{BULGULAR}

Bu bölümde, Covid-19 salgını döneminde, 4 büyük spor kulübünün hisse fiyatlarındaki değişim, trend analizi yöntemi ile hesaplanmış ve sonuçlar grafiklere aktarılmıştır.

Tablo 1'de, Fenerbahçe Futbol A.Ş hisse senetlerindeki trend ve değişimin, pandemi tarihleri ve otoritelerin verdikleri kararlarla uyumlu bir seyirde olduğu gözlenmiştir. 11 Mart 2020 de Türkiye'de ilk vakanın açıklanması ile beraber, sektörde alınan ilk karar, spor müsabakalarının 2020 Nisan sonuna kadar seyircisiz oynatılması olmuştur. Salgının yaygınlaşmasıyla birlikte, kararlar tekrar gözden geçirilmiş ve 19 Martta futbol liglerinin ertelendiği ilan edilmiştir. Sektörde verilen bu karar, Mart 2020 hisse fiyatlarına yansımış ve baz yıl olan 2019 yılına göre, hisselerde yaklaşık \%48'lik bir değer kaybı gerçekleşmiştir. Mart ayındaki değer kaybı bir önceki aya göre ise \%46 civarındadır. Mart ayında Fenerbahçe içinde, pozitif vakalar açıklanmaya başlamış, kulüp yöneticileri çalışanlar ve sporcular arasında sağlık sorunları yaşanmıştır. 3 Nisan 2020'de, ligin en erken, haziran ayı başında başlayacağı ilan edilmiş ve durumun mayıs ayında tekrar değerlendirileceği duyurulmuştur.

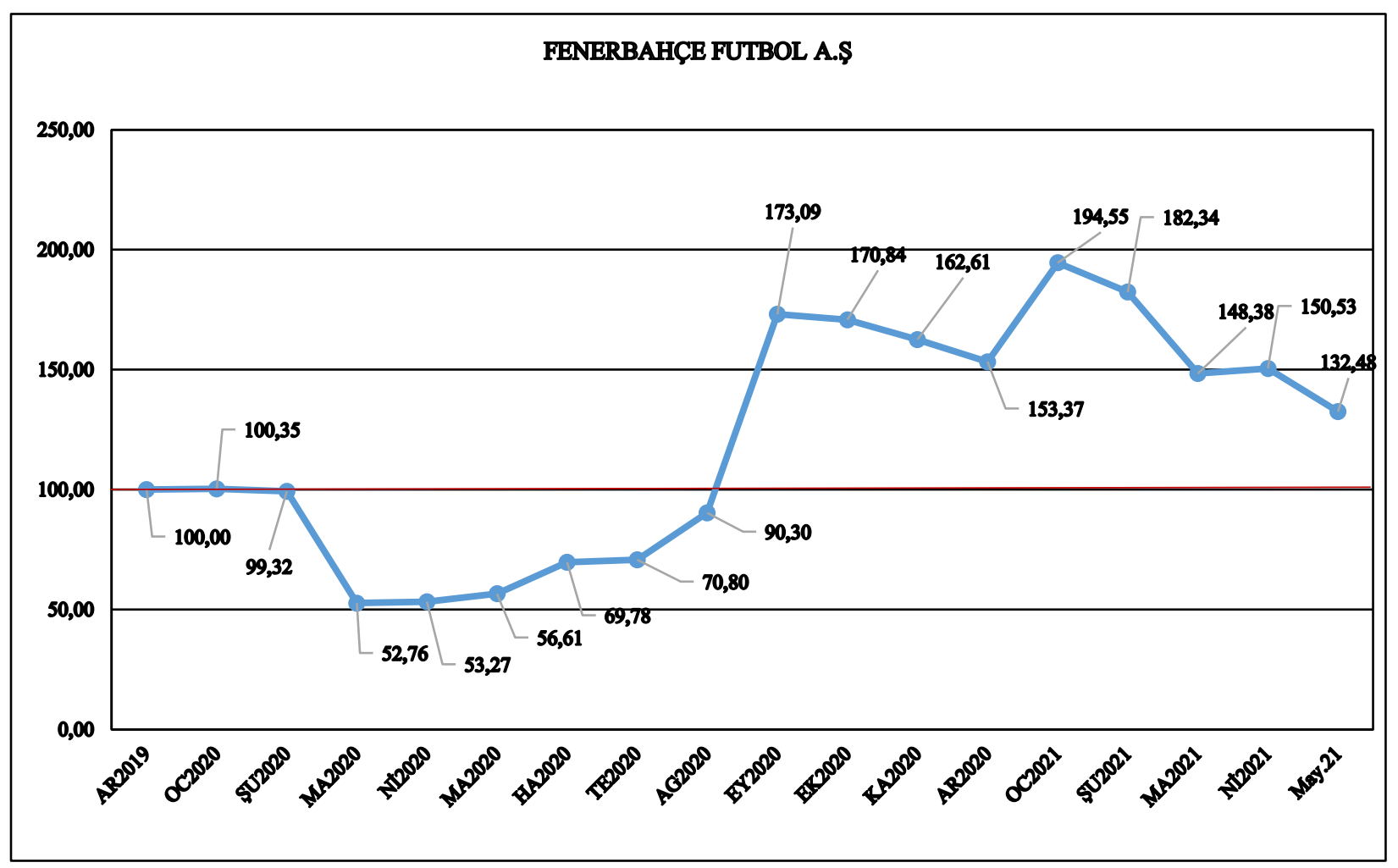

Grafik 1. Pandemi dönemi Fenerbahçe futbol A.Ş hisse senetleri trend analizi

Bu açıklamanın yapıldığı dönemde, hisse değerleri, baz yıla göre 100'ün altında olsa da, bir önceki aya göre hisselerde, yaklaşı \% $15^{\prime}$ lik bir artış meydana gelmiştir. 29 Mayıs tarihinde, 2019-2020 futbol sezonunun kalan tüm maçlarının, seyircisiz de olsa oynatılması kararının açıklanmasıyla, 
Fenerbahçe hisse fiyatlarında iyileşmeler meydana gelmiştir. Haziran ayında transfer sezonunun açılması ile birlikte, ligdeki hareketlilik borsaya yansımış olsa da, Ağustos 2020 ye kadar trend 100 ün altında kalmış ve Fenerbahçe hisselerinde 2019 baz yılına göre değer kayıpları yaşanmıştır. Temmuz sonunda, 2019-2020 sezonunda pandemi nedeniyle küme düşmenin kaldırılması kararı, Ağustos ayı hisse fiyatlarına iyileşme olarak yansımış ve bu iyilik hali Eylül ayında da devam etmiştir. Eylül 2020 hisse fiyatlarında, hem bir önceki aya göre hem de baz yıla göre, çok yüksek bir artış ve iyileşme ortaya çıkmıştır. Hisse fiyatlarının trendi, baz yıla göre 173 hesaplanarak \%73'lere varan iyileşmeler ortaya çıkmıştır. Bir önceki aya göre hisselerin \%91 değer kazandığ görülmektedir. $\mathrm{Bu}$ önemli değer artışının nedeni, Ağustos ayında tüm önemli transferlerin gerçekleşmiş olması ve ligde ortaya çıkan başarılı maç sonuçları olabilse de, salgın nedeniyle alınmış olan olumlu kararların etkisinin, göz ardı edilmemesi gerektiğini düşünmekteyiz. 2020 kış döneminde, hisselerde ciddi bir değer kaybı yaşanmamıştır. Hisselerin trendi 100 ün üzerindedir. Ocak 2021'de Fenerbahçe hisse fiyatları, incelenen dönem için en yüksek değerine ulaşmış, baz yıla göre \%94 lük değer kazanmıştır. 2021 yılında, Emre Belezoğlu takıma dahil olmuş ve Fenerbahçe üst üste galibiyetler elde etmiştir. Bu durum, hisse değerlerine artış olarak yansımıştır. Sınırlı sayıda da olsa, seyircili maçların tekrar başlamış olması, karar vericilerin kriz yönetimi ve salgın yönetiminde tecrübe edinmesi, sektöre olumlu yansımıştır. Nisan ayında futbolcuları aşılama kararları, o tarihe kadar birçok sporcu ve kulüp yöneticisinin hastalığı geçirmiş olması, 2021 yılında sektörü rahatlatmış ve bu durum hisse senetlerine olumlu yansımış olabilir (Bkz Tablo 1).

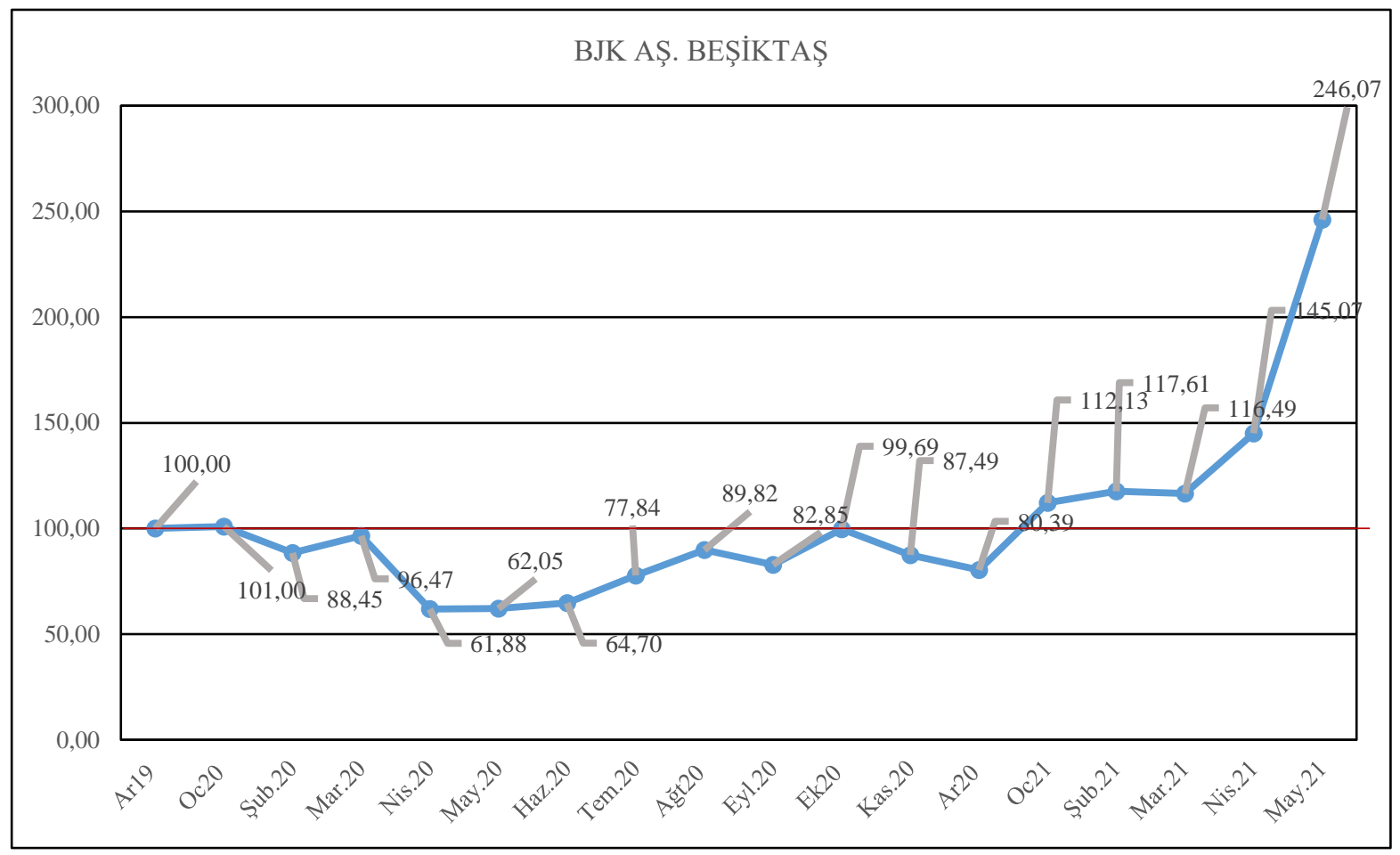

Grafik 2. Pandemi dönemi BJK A.Ş (Beşiktaş) hisse senetleri trend analizi 
Tablo 2'de Beşiktaş Spor Kulübü salgın dönemi hisse fiyatlarındaki değişim ve trend incelendiğinde; hisse fiyatlarında, salgın tarihlerinde yapılan açıklamalarla uyumlu iniş çıkışın ortaya çıktığı görülmektedir. Mart ve nisan aylarında spor müsabakalarının ertelenmesi, devamında ligin ertelenerek mayıs ayına kadar liglere ara verilmesi sürecinde, Beşiktaş hisse fiyatlarında trend, baz yıla göre 60'lara kadar inerek, hisselerde yaklaşık \%40'lara varan değer kayıpları yaşanmıştır. Beşiktaş, Aralık 2020 tarihine kadar, baz yıl ortalamasının altında bir seyir izlemiş ve hisselerin trendi 100 ün altında kalmıştır. Aralık 2020 den sonra trend 100’ün üstüne çıkarak bir önceki aya göre de yükselme eğilimi başlamıştır. Salgın dönemine kötü başlangıç yapan, hisselerinde de ciddi değer kayıpları yaşayan Beşiktaş'ın, Aralık 2020'den Mayıs 2021'e kadar borsa değerleri yükselişe geçmiştir. Hisse değerlerinde rekor denecek düzeyde $\% 150$ ye varan değerlenmeler ortaya çıkmıştır. 2020-2021 sezonunda, Teknik Direktör Sergen Yalçın'la birlikte Beşiktaş, sezonun favori şampiyonlarından görülmüş ve sezonun son maçına kadar, şampiyonluk kupasının kimde kalacağının belirsizliği, hisse fiyatlarını artıımış olabilir. Aynı zamanda hisselerde ortaya çıkan değer artışları, salgında sektörle ilgili olumlu kararların açıklandığı döneme de denk gelmektedir. Beşiktaş hisse fiyatları, pandemi kararları ile uyumlu bir seyir izlemiştir (Bkz. Tablo 2).

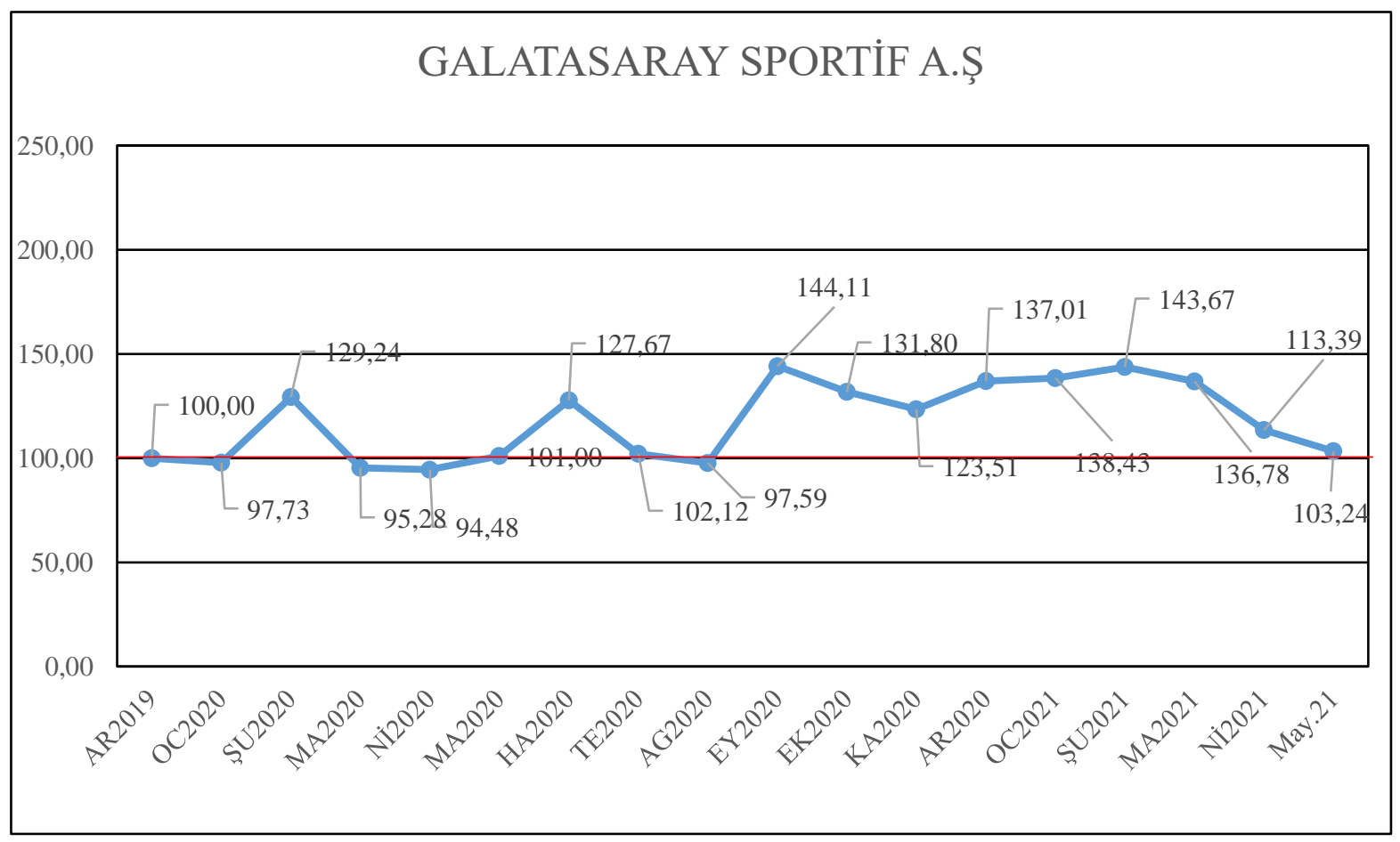

Grafik 3. Pandemi dönemi Galatasaray Sportif A.Ş hisse senetleri trend analizi

Tablo 3 incelendiğinde, Galatasaray Sportif A.Ş Avrupa kupası kazanmış ilk ve tek Türk futbol takımı olarak, en çok taraftarı olan ve borsada yüksek işlem hacmine sahip bir kulüptür. Galatasaray hisseleri, pandemi döneminde diğer takımlara göre daha istikrarlı bir seyir izlemiştir. 
Trendin 100 ün altına düştüğü dönemler pandeminin başlangıcı ve ligle ilgili belirsizliklerin yoğun olarak yaşandığı Mart Nisan Mayıs 2020 ay ortalamalarındadır. Bu aylarda baz yıla göre değer kaybı, \%6'lar civarındadır. Salgının, liglerle ilgili yaratmış olduğu belirsizliğin azalması ile birlikte, Galatasaray A.Ş hisse fiyatları, belli bir istikrarı yakalamış fakat diğer kulüplerin yaşadığı aşırı değerlemeleri yaşamamıştır. 2020 yılında, Galatasaray’ın Başakşehir ile vermiş olduğu şampiyonluk mücadelesi sayesinde, kriz firsata dönüşmüş ve hisse fiyatları baz yıl değerlerinin altına inmemiş olabilir. Pandemi dönemi hisselerdeki en büyük değer artış1, 2020 eylül ayında ortaya çıkmış, hisse fiyatları baz yıla göre yaklaşık \% 44 değerlenmiştir. Bu iyilik ve istikrarlı hal, 2021 Mart ayına kadar devam etmiştir. Şubat 2021'den sonra kulüp hisseleri, bir önceki aya göre değer kaybı yaşamaya başlamış, Şubat 2021'de 143 olan trend, Mayıs 2021 'de yaklaşık \%40 değer kaybı ile 103'lere kadar gerilemiştir. Bu kayıplar, salgının sektörde yarattığı etkiyle ortaya çıkmış olabileceği gibi, 2021 yılının başından itibaren Fatih Terim ve kulüp başkanı arasında ortaya çıkan ayrışmalar nedeniyle de ortaya çıkmış olabilir. Galatasaray hisselerinin pandemi döneminde, genel olarak istikrarı ve iyilik halinin diğer bir nedeni de, Galatasaray'ın 20 y1l aradan sonra Fenerbahçe'yi kendi sahasında ilk defa yenmiş olması olabilir (Bkz Tablo 3).

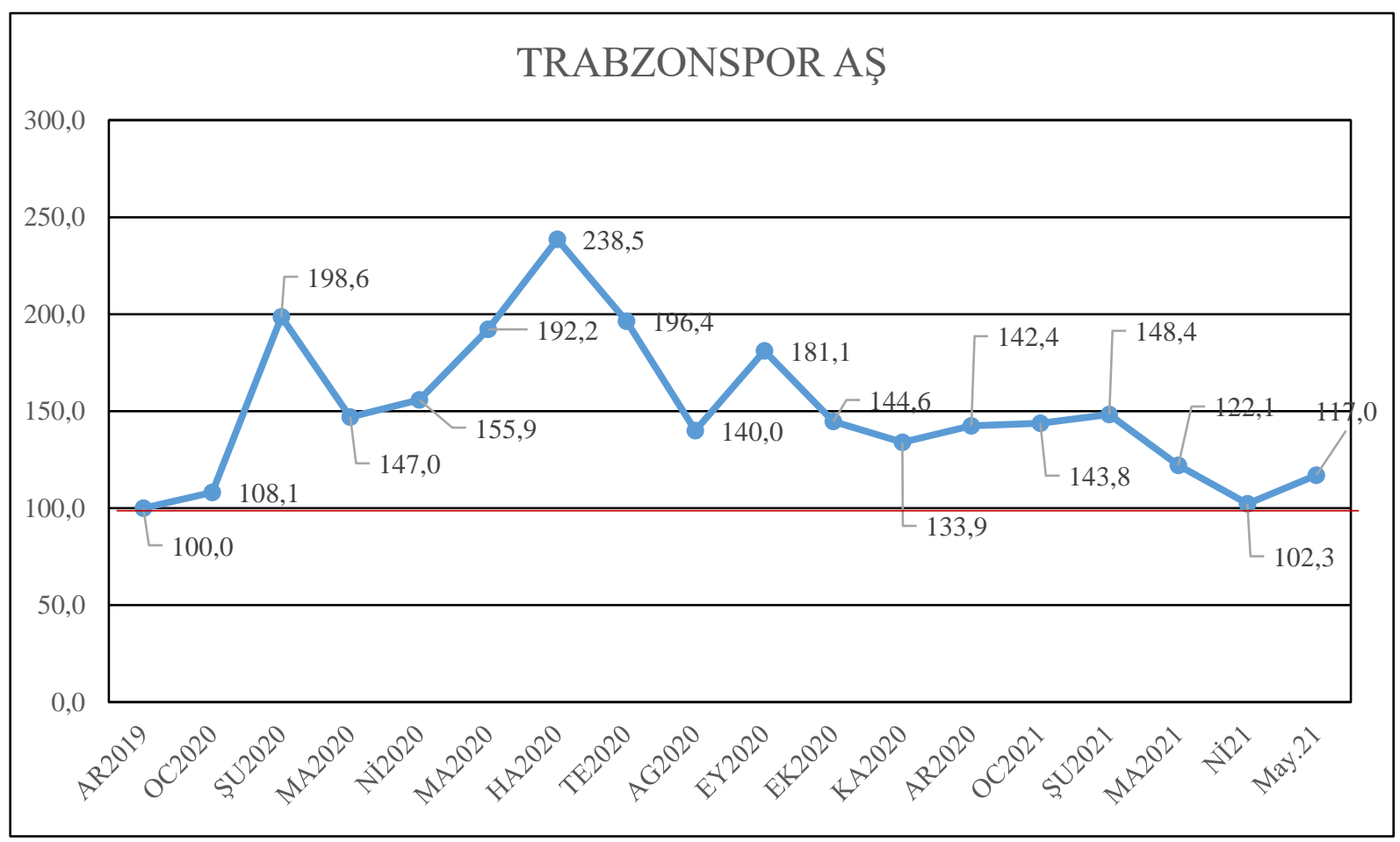

Grafik 4. Pandemi dönemi Trabzonspor A.Ş hisse senetleri trend analizi

Tablo 4'te görüleceği üzere, Trabzonspor hisselerinin trendi, baz yıla göre 100'ün altına inmemiş ve salgın döneminde negatif değerler almamıştır. Pandemi döneminde, hisseleri baz yıla göre değer kaybetmeyen tek takım Trabzonspor olmuştur. Bu durum futbol taraftarının reflekslerinden kaynaklanmış olabileceği gibi, Mart 2020 yılında Trabzonspor'un Başakşehir ile birlikte şampiyonluk yolunda favori iki takım olarak mücadele etmesi hisse fiyatlarına istikrar olarak 
yansımış olabilir. Ayrıca, Trabzonspor 2019, 2020 ve 2021 yılı futbol sezonlarında transferlerden yüksek gelir elde eden bir takım olduğu için, hisse fiyatları baz yıl değerlerinin altına inmemiş olabilir. Ancak trendin eğilimi diğer takımlarla benzer görüntüdedir. Bir önceki aya göre değişimlerin trendi izlendiğinde, pandemi döneminde futbol sektörü için alınan önemli kararların açıklandığı tarihlerde iniş ve çıkışları izlemek ve eğilimi salgının seyriyle yorumlamak mümkündür. Pandemi nedeniyle süper ligin süresiz olarak ötelendiği Mart 2020 tarihinde, hisse senedi ortalamaları, bir önceki aya göre 198'den 147'e düşerek, hisselerde yaklaşık, \%51 değer kaybı ortaya çıkmıştır. Salgın nedeniyle süper ligde ertelenen maçların, Haziran 2020'de tekrar oynanmaya başlamasıyla trend, 238 'lere kadar yükselmiş, bir önceki aya göre hisseler $\% 46$ değer artışı ile, incelenen dönemde en yüksek hisse senedi ortalaması değerine ulaşmıştır. Eylül 2020 tarihinde seyircisiz de olsa yeni sezonun başlangıcı kararı, hisselerin pik yaptığı diğer bir dönem olarak göze çarpmaktadır. UEFA tarafından finansal yükümlülüklerini yerine getirmediği gerekçesiyle, Avrupa kupalarından bir yıl men edilmesi kararına ve salgının sektörde yarattığı olumsuz duruma rağmen, her ne kadar bir önceki döneme göre pandemiden etkilenip değer kayıpları yaşamış olsa da, Trabzonspor hisseleri BİST'te baz yıla göre negatif değer almamış tek kulüptür (Bkz. Tablo 4).

\section{TARTIŞMA VE SONUÇ}

Koronavirüs salgını döneminde, tüm sektörlerde derin ekonomik kayıplar yaşanmıştır. Spor endüstrisi de salgından etkilenen önemli sektörlerden biridir. Belirsizlikler, kapanmalar, ertelenmeler ve iptal edilen maçlar, spor endüstrisi içinde büyük bir yer kaplayan futbol ekonomisini derinden sarsmış, kulüplerde ciddi gelir kayıplarına neden olmuştur. Çalışma, futbol ekonomisi içinde, önemli bir gelir kaynağı olan borsa gelirleri, hisse senedi değerlerindeki değişimi, salgın döneminde incelemek amacıyla yapılımıştır. Çalışma, nedensellik bağı kurmaktan ziyade, salgın döneminde, sektörde futbol otoriteleri tarafından alınan kararların, hisse senedi fiyatlarına yansımalarını gözler önüne sermek ve kulüp hisselerinin salgın dönemindeki eğilimini (trendini) görmek amacıyla yapılmıştır.

Kriz ve olağanüstü dönemlerde, sosyal, toplumsal, ekonomik yapı, kaçınılmaz bir şekilde olumsuz etkilenmektedir. Fakat olağanüstü dönemlerin ekonomik yansımaları, aynı sektörde olan işletmeler için dahi farklı olabilmektedir. Futbol sektöründe de genel olarak tüm kulüpler salgından olumsuz olarak etkilenmişse de, bazı kulüplerin hisseleri kriz karşısında daha güçlü bir seyir izlemeyi başarmıştır. Çalışmamızda, salgın döneminde kulüplerin hisse senetleri ortalamalarında, baz yıla göre \%50'lere varan değer kayıpları yaşanırken (Fenerbahçe ve Beşiktaş gibi), Galatasaray'da baz yıla göre en düşük değer kaybı yaklaşık \%6'lar civarındadır. Trabzonspor hisse senetleri baz yıla göre negatif değerler almamıştır. Her ne kadar Galatasaray ve Trabzonspor daha istikrarlı görünse de, bir önceki aya göre (bkz. Tablo3-4) trend incelendiğinde, bu iki kulüp için de \%50’lere varan değer kayıpları gözlenmiştir. Salgın döneminde alınan kararlar, kararın sektör 
içinde olumlu ya da olumsuz karşılanmasına göre, tüm kulüplerin hisselerinde değişime neden olmuştur. Aynı zamanda, kulüp başkanları, yöneticiler, sporcular, salgın süresince hastalığa yakalanmış ya da temaslı olarak karantina süreçlerinde kalmışlardır. Bu durum bedensel performansı düşürmekle birlikte, ekonomik değerlemeleri de kaçınılmaz olarak, olumsuz etkilemiş̧ir. Sonuç olarak, Covid-19 salgın döneminde, sektörde alınan kararların hisse senetlerine tarihler itibari ile yansıdığı gözlemlenmiştir. Kulüplerin hisse senedi ortalamalarında, baz yıl ve bir önceki aya göre yaklaşık \%50’lere varan değer kayıpları hesaplanmıştır.

\section{ÖNERILLER}

Spor, yapısı ve ruhu gereği esnek, değiş̧en koşullara hızlı adapte olması gereken bir sektördür. Olağanüstü kriz dönemlerinde, karar vericiler ve yöneticiler, daha seri tedbirlerle koşullara yanıt verebilir ve esneyebilirse, sektör krizden daha az etkilenecektir. Salgın, hiç hayal edilemeyecek koşulları beraberinde getirdiği için, sporun esnek yapısının, şaşkınlık dönemi ile birlikte kararlara yansımasının geç olduğu gözlenmiştir.

Spor otoriteleri ve hükümetler kriz eylem planları hazırlamalıdır. Sınırlı seyirci ve geniş önlemlerle, taraftarlar tekrar tribünlere dönmelidir. Müsabakalar, alınacak tedbirlerle yapılır hale getirilmelidir. Sporcuların aşılanması ve aşısız taraftarın tribünlere alınmaması kararı, her ne kadar bazı grupları rahatsız etmiş olsa da, sektörün hızlı toparlanması için önemli bir tedbirdir.

Çıkar Çatışması: Yazarlar arasında herhangi bir çıkar çatışması yoktur.

Yayın Etiği: Mevcut çalışmanın yazım sürecinde "Yükseköğretim Kurumları Bilimsel Araştırma ve Yayın Etiği Yönergesi” kapsamında bilimsel, etik ve alıntı kurallarına uyulmuş olup; toplanan veriler üzerinde herhangi bir tahrifat yapılmamış ve bu çalışma herhangi başka bir akademik yayın ortamına değerlendirme için gönderilmemiştir. 
Yurtsızoğlu, Z. (2021). Salgın dönemi hisse değerlerinde ekonomik kayıplar (Trend analizi). Avrasya Spor Bilimleri ve Ĕ̈itim Dergisi, 3(1), 128-140.

\section{KAYNAKÇA}

Akşar, T. (2005). Endüstriyel Futbol. İstanbul: Literatür Yayınları.

Authier, C. (2002). Futbol A.Ş. İstanbul: Kitap Yayınevi.

Bebek, Ö. (2017). Tüketicilerin spor sponsorluğu algıları ve sponsorluğun tüketici davranışlarına etkileri (Sakaryaspor kulübü örneği). (Yüksek Lisans Tezi). Sakarya Üniversitesi, Eğitim Bilimleri Enstitüsü. Sakarya.

Güngör Akpınar, F. (2020). http://www.tuyid.org/files/makaleler/EBulten_10_sayi_FGA.pdf

Borsaİstanbul. (2021). https://borsaistanbul.com/tr/sayfa/860/sirketler.

Borsaİstanbul, KAP. (2021). https://borsaistanbul.com/tr/sayfa/207/kamuyu-aydinlatma-platformu

Business Wire, (2020). Business Wire. Sports publishing - \$614 billion global market opportunities and strategies. Retrieved from https ://www.business wire.com/n ews/h ome/2 01905 14005 472/e n/Sports614BillionGlobal-MarktOpportunities.

Dalifinans. (2021). https://www.dalifinans.com /trend-egilim-yuzdeleri-analizi.

İşyatırım. (2021). https://www.isyatirim.com.tr/tr-tr/analiz/hisse/Sayfalar/Tarihsel-Fiyat-Bilgileri.aspx.

Kamu Aydınlatma Platformu KAP. (2021). https://www.kap.org.tr/tr/bist-sirketler.

Karadeniz, E. ve Kahiloğullari, S. (2014). Borsa İstanbul'da işlem gören spor şirketlerinin finansal performansının oran yöntemiyle analizi. Çukurova Üniversitesi Sosyal Bilimler Enstitüsü Dergisi, 23(2), 129-144.

Kurumlar Vergisi Kanunu. (2016, 13 Haziran). Resmî Gazete Sayıs1: 26205.

Taşkın, A. ve Eren, T. (2016). UEFA Şampiyonlar liginde forvet oyuncularının performanslarının çok ölçütlü karar verme yöntemleri ile değerlendirilmesi. Celal Bayar Üniversitesi Sosyal Bilimler Dergisi, 14(1), 79-106.

Yurtsızoğlu, Z. (2021). Spor endüstrisinde bir krizin öyküsü (Covid-19). Sivas Cumhuriyet Üniversitesi Spor

Bilimleri Dergisi, 2(1), 45-50. 


\section{EXTENDED ABSTRACT}

\section{Economic Losses in Club Values in The Pandemic Period (Trend Analysis)}

\section{Introduction}

Football economy has become a major economic power within the sports industry with matchday ticket sales, sponsorship revenues, broadcasting revenues, advertising revenues, testimonial and transfer revenues, licensed product sales and stock market revenues.

Football clubs have started to offer their shares to the public in the stock market by structuring as a joint stock company. For clubs, the stock market has become an important source of income. Fenerbahçe, Galatasaray, Beşiktaş, Trabzonspor offered their shares to the public in order to obtain funds at lower costs and to generate income for their corporate clubs. With this method, they became more institutional and started to generate income from the capital markets.

The pandemic has affected the stock market revenues as well as all the revenues of the clubs. The study was carried out to examine the economic value losses in the stocks of 4 big clubs (Fenerbahçe, Galatasaray, Beşiktaş, Trabzonspor), which were in the super league and whose shares were traded on the BIST (Borsa Istanbul) during the Covid-19 Global pandemic. The data received from BIST was subjected to trend analysis by going through a series of processes. In the study, using the trend analysis method, the value losses that occurred in the pandemic were analyzed, and solutions were tried to be created for the compensation of these losses. The study is important in that it set light to on a part of the football economy and offers potential solutions in the ongoing pandemic.

\section{Method}

In Turkey, Fenerbahçe Sports Club, Beşiktaş Gymnastics Club, Galatasaray Sports Club, Trabzonspor Club, which have offered their shares to the public in the Super League and are traded on the BIST, are included in the study. The analysis covers the 18-month period from December 2019 to May 2021. The research is a cross-sectional study, reflecting the situation that occurred during the months in which the study was included. In the study, changes in share values were evaluated under pandemic conditions, ignoring other conditions.

In the study, arithmetic average, weighted averages, corrections, inflation adjustment, monthly \% changes and trend analysis were performed. In the trend analysis technique, the financial movements of the enterprises in the past period are analyzed by years or periods. The direction of the trends, that is, increases or decreases in the past periods, sheds light on the examined periods.

\section{Findings}

In times of emergency and crisis, the social, social and economic structure is inevitably adversely affected. However, the economic reflections of extraordinary periods can be different even for businesses in the same sector. In the football sector, although all clubs were negatively affected by the pandemic, the shares of some clubs managed to follow a stronger course. In our study, while 
the average value of the stocks of the clubs decreased by $50 \%$ compared to the base year (such as Fenerbahçe and Beşiktaş) during the pandemic period, the lowest value loss in Galatasaray was around 6\% compared to the base year. Trabzonspor stocks did not receive negative values compared to the base year. Although Galatasaray and Trabzonspor seem to be more stable, when the trend analyze compared to the previous month, depreciation of up to $50 \%$ was observed for these two clubs. The decisions taken during the pandemic period caused a change in the shares of all clubs, depending the decision was received positively or negatively within the sector. At the same time, club presidents, managers, athletes have been infected with the disease or have been in quarantine processes during the pandemic. While this situation reduced physical performance, it negatively affected economic valuations

\section{Discussion and Conclusion}

Due to its structure and spirit, sports is a flexible industry that needs to adapt quickly to changing conditions. In times of extraordinary crisis, if decision makers and managers can respond and flex with more rapid measures, the industry will be less affected by the crisis. Since the pandemic brought with it unimaginable conditions, it has been observed that the flexible structure of sports is reflected in the decisions together with the period of surprise.

Sports authorities and governments should prepare crisis action plans. With limited spectators and extensive precautions, fans must return to the stands. Competitions should be made possible with the measures to be taken. The decision to vaccinate the athletes and not to allow the unvaccinated fans to the stands is an important precaution for the rapid recovery of the industry, although it has disturbed some groups. 